\title{
Open Access of Publications by Veterinary Faculty in the United States and Canada
}

André J. Nault

\begin{abstract}
The free availability of full-text veterinary publications in MEDLINE-indexed journals by US and Canadian veterinary faculty from 2006-7 was determined. Additionally, publishing databases were searched to obtain general statistics on veterinary publishing. A survey of institutional initiatives to promote open-access journals and institutional repositories was also performed. Veterinary faculty published a total of 4,872 articles indexed by MEDLINE in 679 different journals. Of these articles, 1,334 (27\%) were available as free full text and were published in 245 different journals. Although 51 veterinary-specific journals offering immediate and free full-text access were identified, few articles in this study appeared in these titles. Rather, most free scholarly articles by veterinary faculty appeared in journals with an embargo period. Academic veterinary institutions may want to recommend acceptance of alternate forms of information dissemination (such as open-access journals and journals published only digitally) to encourage greater global dissemination of their research findings. The promotion and use of digital institutional repositories is also an area for future investment and warrants additional research.
\end{abstract}

Key words: communication, research, open access, publishing economics

\section{INTRODUCTION}

Scholarly veterinary journals remain the primary method for dissemination of new professional knowledge, which constitutes a key resource in veterinary education for faculty, residents, staff, and students. It also plays an important role in the continuing education of practicing veterinarians. Commercial publishers such as Elsevier, Wiley-Blackwell, and Springer each publish multiple veterinary journals. Most of the remaining journals are published by small scholarly societies or associations. Access to veterinary journal articles is usually limited by subscription costs, but some are available free immediately or after a short embargo period. In academic publishing, an "embargo period" is defined as a period of time after which access to the full text of the article is freely available to non-subscribers. A large percentage of new veterinary publications are authored by faculty, staff, and students at 33 veterinary colleges in the United States and Canada, but to what extent is this information available free of charge to all who want to read it?

Within the past 15 years, users of academic libraries have come to favor electronic journals for their search features and remote accessibility, although many still prefer the print version for reading. ${ }^{1,2}$ As a result, demands have been placed on libraries to subscribe to both print and online versions of a journal, creating a heavy budgetary burden. Additionally, the pricing schemes of many journals have outpaced inflation, forcing librarians to allocate a greater percentage of the library's budget each year to subscription costs. ${ }^{3}$ The end result has often been the elimination of print versions in favor of the electronic version alone. Veterinarians in private practice also use electronic resources extensively to stay current. ${ }^{4}$

In developing countries, access to current research has always been difficult. Starting in 2002, however, the
World Health Organization fostered the HINARI ${ }^{5}$ and AGORA Program ${ }^{6}$ in collaboration with the largest publishing companies to allow 109 low-income countries, areas, and territories free or very low-cost access to more than 7,000 journals. Veterinary faculty in these countries automatically qualify for free access. This access has helped ease the financial burden for countries least able to afford subscriptions, although poor technology infrastructure is still a major impediment to information access in these countries. $^{7}$

Between 1986 and 2006, research libraries' expenditures for journals increased by $321 \%, 8$ whereas the consumer price index rose $92 \%$ during the same time period. ${ }^{9}$ How have publishers been able to raise their prices without loss of revenue? Simply stated, scientific journals do not obey the normal market rule of supply and demand. The end users, typically faculty, do not pay for the journal, their institutional libraries do. Faculty may want to see their articles reach all potential readers and thus maximize citations and scientific impact, but for-profit publishers also want to maximize revenue. Ironically, while faculty write and review journal articles without financial reward, their libraries are experiencing a financial crisis trying to buy these same products back from publishers.

Some believe that the traditional subscription-based model is becoming increasingly unsustainable. Although increasing volumes of information are being published, library budgets have remained static or are declining. These subscription and budget conflicts have been felt across many disciplines in academic libraries, creating additional interest in the open-access (OA) movement. For the purpose of this article, "OA" is defined as the free and permanent online access to the full text of research articles; this access includes those articles available after a typical embargo period of 6 months to 1 year. Although 
the roots of the modern OA movement can be traced to the 1960s, not until the advent of the Internet were publishing costs significantly reduced enough to allow the application of this new publishing model. The core philosophy of the OA movement maintains that new discoveries and information are meant to be shared, not limited by restrictive copyright ownership or cost barriers. The faster and more easily that new veterinary information can be shared, the sooner it can lead to improvements in animal and human health and care and contribute to other new discoveries. The National Institutes of Health (NIH) mandate in April 2008 supported and applied this philosophy. ${ }^{10}$ This mandate requires that scientists receiving NIH funding submit final peerreviewed journal manuscripts to the digital archive PubMed Central on acceptance for publication.

Commercial publishers have also become involved in the OA movement. Springer's acquisition of the science, technology, and medicine (STM) publisher BioMed Central in 2008 was an acknowledgment that the OA movement was not a passing fad. BioMed Central was one of the pioneers of the OA publishing model. Springer has acknowledged that it sees OA publishing as an "important and sustainable part of STM publishing."11

Access to veterinary journal articles is usually hindered by subscription costs. In the past decade, OA initiatives have attempted to reduce these restrictions to information sharing through promotion of new publishing models and educating authors on their options. But all publishing has expenses, and for OA someone other than the reader must pay for the publication. How this financial support might be generated has been extensively discussed but is so far unresolved. At the present time, most veterinary journals are not immediately OA or available after a six-month or one-year embargo.

Although most studies have demonstrated a positive correlation between citation rates and free online availability, ${ }^{12-15}$ the causative factors are not completely understood. ${ }^{16,17}$ Regardless of the cause, citation rate as an index of a given article's value fails to consider the impact on end users, including practicing veterinarians, animal-health professionals, and animal producers who benefit from free access to vital information. Indeed, recent research has made a compelling argument that OA most benefits end users in poor countries, in which subscription costs are a major impediment to accessing information. ${ }^{18,19}$ There is also a general understanding that the types of materials cited in research articles vary widely by discipline, and many of the pioneering articles in OA bibliometrics have used articles published in the fields of physics and computer science.

The global need for access to veterinary and animal science information related to the use of animal models for human diseases, zoonotic threats such as bovine spongiform encephalopathy, and the increasingly interdisciplinary approach to science has increased. Therefore, the purpose of this article is to evaluate the accessibility of research published by faculty, staff, and students at veterinary schools in the United States and Canada and the factors accounting for any inter-institutional differences.

\section{MATERIALS AND METHODS}

Search strings were constructed in PubMed ${ }^{20}$ to search the MEDLINE database and recover articles published by faculty, staff, and students at 31 veterinary colleges and schools in the United States and Canada between January 1, 2006, and December 31, 2007 (the College of Veterinary Medicine at Western University of Health Sciences and the University of Calgary Faculty of Veterinary Medicine were not included in this study because they had only recently been established). This time frame was chosen for two reasons. First, it was recent enough to be timely, and second, journals beyond a 1-year embargo could be identified. Additionally, it was a large enough temporal window to provide a sufficient number of records to reflect a school's scholarly output. Although faculty typically author most research publications at veterinary schools and colleges, it was not possible to build a search in PubMed that would restrict results to only faculty authors. As a result, although publications in this article are referred to as "faculty publications," readers should understand that some staff and student publications may also be represented in the results. Several schools required more sophisticated search strings because of an organizational structure that either removed the word "veterinary" from the address field in MEDLINE records or had information in the address field that could result in erroneous records (e.g., "il" could be an abbreviation for Italy in an e-mail address or the abbreviation for Illinois). All PubMed searches were performed on April 10, 2009. The citations from each search were reviewed individually to verify the appropriate institution affiliation. Citations from searches were compiled into a RefWorks ${ }^{21}$ account for tabulation and analysis. Two searches were run for each institution: the first to identify all articles and the second to limit articles to those available as free full-text. An example of a search string used for the University of Minnesota is (university[ad] OR college[ad]) AND (minnesota[ad] OR mn[ad]) AND veterinary[ad] AND ("loattrfree full text"[sb]) AND (“2006/01/01"[PDAT] : “2007/12/31"[PDAT]).

Customization of search strings used was sometimes necessary to avoid erroneous records, and inclusion of zip code, city names, and other information allowed precise searches for individual institutions conferring the doctorate of veterinary medicine degree (DVM or VMD). It is important to note that the MEDLINE address field indicates the institutional affiliation for only the first author of an article as published in the journal. In addition, information for this field is taken as is from the published article. Therefore, these search strings can only harvest these specific articles and are not meant to represent the complete scholarly output of an institution. Also, MEDLINE indexes only journals and not conferences, symposiums, or other meetings, and the list of veterinary journals it indexes is not comprehensive. Finally, it is common knowledge that because of inconsistencies in the address field of MEDLINE records, some records will be missed. However, the goal of the query was only to compare institutions by using the same search strategy in the same database and to have a large enough representative sample overall. The goal was not 
Table 1: MEDLINE-indexed journal titles containing 10 or more free full-text articles produced by US and Canadian veterinary schools and colleges, 2006-7

\begin{tabular}{|c|c|c|c|}
\hline Journal title & $\begin{array}{l}\text { Number of } \\
\text { open-access articles }\end{array}$ & $\begin{array}{l}\text { Rank among } \\
\text { open-access journals }\end{array}$ & $\begin{array}{l}\text { Rank among } \\
\text { all journals }\end{array}$ \\
\hline Canadian Veterinary Journal & 147 & 1 & 4 \\
\hline Journal of Veterinary Diagnostic Investigation & 87 & 2 & 6 \\
\hline Veterinary Pathology & 76 & 3 & 10 \\
\hline Infection and Immunity & 59 & 4 & 16 \\
\hline Journal of Virology & 49 & 5 & 20 \\
\hline Journal of Dairy Science & 48 & 6 & 22 \\
\hline Journal of Wildlife Diseases & 43 & 7 & 26 \\
\hline Canadian Journal of Veterinary Research & 37 & 8 & 28 \\
\hline Applied and Environmental Microbiology & 33 & 9 & 32 \\
\hline Journal of Immunology & 28 & 10 & 36 \\
\hline Journal of Biological Chemistry & 25 & 11 & 42 \\
\hline Clinical and Vaccine Immunology & 22 & 12 & 40 \\
\hline Reproduction & 22 & 13 & 41 \\
\hline Toxicological Sciences & 21 & 14 & 46 \\
\hline Biology of Reproduction & 18 & 15 & 61 \\
\hline Endocrinology & 17 & 16 & 53 \\
\hline Journal of Bacteriology & 16 & 17 & 55 \\
\hline Journal of Clinical Microbiology & 14 & 18 & 65 \\
\hline Journal of General Virology & 13 & 19 & 68 \\
\hline Journal of Applied Physiology & 11 & 20 & 82 \\
\hline $\begin{array}{l}\text { Proceedings of the National Academy of Sciences of the } \\
\text { United States of America }\end{array}$ & 11 & 21 & 85 \\
\hline Journal of Nutrition & 11 & 22 & 86 \\
\hline Antimicrobial Agents and Chemotherapy & 10 & 23 & 77 \\
\hline Emerging Infectious Diseases & 10 & 24 & 66 \\
\hline Journal of Animal Science & 10 & 25 & 81 \\
\hline Microbiology & 10 & 26 & 84 \\
\hline
\end{tabular}

to gather all articles published by faculty, staff, and students at each institution.

Librarians at each veterinary institution were then sent e-mails with the number of articles identified and asked whether (a) any initiatives were underway at their institution to educate faculty and students on their publishing options as authors and what the perceived success of these promotions was and (b) tenure requirements at their institution specifically mentioned alternative forms of information dissemination such as electronic journals, OA journals, or digital institutional repositories (IRs). Phone calls were placed when librarians did not respond to e-mails. During the phone calls, librarians were asked for the same information as in the e-mail. One university declined to participate.

\section{RESULTS}

During the 2006-7 calendar period, veterinary schools and colleges in the United States and Canada published 4,872 MEDLINE-indexed articles in 679 different journal for an average of 157 articles per school or college. One hundred sixty-five articles listed more than one academic institution in the MEDLINE address field, which typically indicates a dual appointment or a move between institutions. The number of articles published by a given veterinary school or college ranged from 448 to 11 .

Of these articles, 1,334 (26\%) were available as free full text and were published in 245 different journal titles. Table 1 lists those journals publishing 10 or more articles as free full text. Of these 26 journals, only one, Emerging Infectious Diseases, offered free and immediate access to its content. The remaining journals had three-month $(n=2)$, six-month $(n=8), 12$-month $(n=14)$, or 18-month $(n=1)$ embargo periods.

Western College of Veterinary Medicine in Saskatchewan produced the largest percentage of articles available as free full text (56\%; see Table 2). The Universite de Montreal and the University of Pennsylvania followed, each with $39 \%$. It is interesting to note that three of the top four academic institutions publishing in OA journals or depositing copies in PubMed Central were Canadian. 
Table 2: Total number of MEDLINE-indexed and free full-text availability of journal articles produced by American and Canadian veterinary schools and colleges

\begin{tabular}{|c|c|c|c|}
\hline Academic institution & $\begin{array}{l}2006-7 \\
\text { publications }\end{array}$ & $\begin{array}{l}2006-7 \\
\text { open-access } \\
\text { publications }\end{array}$ & $\begin{array}{l}\% \\
\text { open access }\end{array}$ \\
\hline Western College of Veterinary Medicine, University of Saskatchewan & 166 & 93 & 56 \\
\hline Université de Montreal & 148 & 58 & 39 \\
\hline University of Pennsylvania & 365 & 142 & 39 \\
\hline Atlantic Veterinary College, Prince Edward Island & 94 & 36 & 38 \\
\hline lowa State University & 144 & 54 & 37 \\
\hline Cornell University & 290 & 105 & 36 \\
\hline Oregon State University & 58 & 18 & 31 \\
\hline Washington State University & 158 & 49 & 31 \\
\hline University of Minnesota & 231 & 67 & 29 \\
\hline Texas A \& M University & 240 & 66 & 27 \\
\hline Louisiana State University & 113 & 30 & 26 \\
\hline Mississippi State University & 84 & 22 & 26 \\
\hline University of Tennessee & 128 & 32 & 25 \\
\hline Guelph University & 216 & 53 & 24 \\
\hline Purdue University & 104 & 25 & 24 \\
\hline University of Wisconsin & 189 & 45 & 24 \\
\hline University of Missouri & 136 & 32 & 23 \\
\hline Ohio State University & 219 & 51 & 23 \\
\hline North Carolina State University & 224 & 50 & 22 \\
\hline University of Illinois & 131 & 29 & 22 \\
\hline University of Georgia & 187 & 41 & 22 \\
\hline Oklahoma State University & 104 & 22 & 21 \\
\hline Colorado State University & 165 & 33 & 20 \\
\hline Virginia-Maryland Regional College of Veterinary Medicine & 127 & 24 & 19 \\
\hline Tuskegee University & 11 & 2 & 18 \\
\hline University of Florida & 182 & 33 & 18 \\
\hline University of California, Davis & 448 & 81 & 18 \\
\hline Tufts University & 93 & 15 & 16 \\
\hline Michigan State University & 110 & 17 & 15 \\
\hline Kansas State University & 81 & 12 & 15 \\
\hline Auburn University & 91 & 8 & 09 \\
\hline
\end{tabular}

It is difficult to determine precisely the number of scholarly veterinary journals currently being published, in part because of insufficient indexing in databases. Language barriers and irregular publication schedules also added to the difficulty. The overlap between veterinary and other basic sciences allows multidisciplinary studies to be published in the same journal, and defining a journal title as "veterinary" is also problematic. Table 1 lists journal titles that are often broad in scope. In reviewing the information available at Ulrichsweb at the end of 2010,22 an online global serials directory, and the Directory of Open Access Journals (DOAJ), ${ }^{23} 353$ scholarly or trade veterinary journals were identified. Of these journals, 186 were available electronically and 51 offered immediate free full-text availability (Table 3 ). Only three journals contained articles $(n=8)$ written by faculty, staff, or students at American or Canadian veterinary schools during the 2006-7 period. Therefore, one can extrapolate that approximately $14 \%$ (51 of 353) of all veterinary journals offer immediate and free access to content. Of the 353 veterinary titles, 65 were published in North America, and most of these titles were small publications distinct from large multinational publishers that have corporate headquarters in non-North American countries but that usually have a major presence in North America.

Determining the number of veterinary-specific journals that offer free access to articles after an embargo period was more difficult. For an approximation, the list of 353 journals was sorted by publisher and electronic availability; those only available in print or already identified as being OA were removed. In addition, journal titles by 
Table 3: Veterinary scholarly or trade journals offering immediate and free full-text access currently in publication, with country of origin

\begin{tabular}{|c|c|}
\hline Title & Country \\
\hline Acta Scientiae Veterinariae & Brazil \\
\hline Acta Scientiarum/Animal Sciences & Brazil \\
\hline Acta Veterinaria Brno & Czech Republic \\
\hline Acta Veterinaria Scandinavica ${ }^{a}$ & United Kingdom \\
\hline American Journal of Animal and Veterinary Sciences & United States \\
\hline Analecta Veterinaria & Argentina \\
\hline Animal Biology and Animal Husbandry & Romania \\
\hline Animal Reproduction & Brazil \\
\hline Archives of Veterinary Science & Brazil \\
\hline Archivos de Medicina Veterinaria & Chile \\
\hline Archivos de Zootecnia & Spain \\
\hline Arquivo Brasileiro de Medicina Veterinaria e Zootecnia & Brazil \\
\hline BMC Veterinary Researcha & United Kingdom \\
\hline Bangladesh Journal of Veterinary Medicine & Bangladesh \\
\hline Bulgarian Journal of Veterinary Medicine & Bulgaria \\
\hline Ciencia Animal Brasileira & Brazil \\
\hline Ciencia Rural & Brazil \\
\hline Human and Veterinary Medicine & Romania \\
\hline International Journal of Animal and Veterinary Advances & United Kingdom \\
\hline International Journal of Applied Research in Veterinary Medicine & United States \\
\hline InVet: investigacion Veterinaria & Argentina \\
\hline Iraqi Journal of Veterinary Sciences & Iraq \\
\hline Israel Journal of Veterinary Medicine & Israel \\
\hline Istituto Superiore di Sanita: Annali & Italy \\
\hline Italian Journal of Animal Science & Italy \\
\hline Journal of Animal and Veterinary Advances & Pakistan \\
\hline Journal of Reproduction and Development & Japan \\
\hline Journal of Veterinary Medical Science & Japan \\
\hline Journal of Veterinary Sciencea & South Korea \\
\hline Pakistan Veterinary Journal & Pakistan \\
\hline Pesquisa Veterinaria Brasileira & Brazil \\
\hline Research Journal of Animal and Veterinary Sciences & Pakistan \\
\hline Revista Brasileira de Zootecnia & Brazil \\
\hline Revista Cientifica Universidad del Zulia & Venezuela \\
\hline Revista Colombiana de Ciencias Pecuarias & Colombia \\
\hline Revista de Investigaciones Veterinarias del Peru & Peru \\
\hline Revista Electronica de Veterinaria & Spain \\
\hline Revista M V Z Cordoba & Colombia \\
\hline Revista Universidad Central de Venezuela & Venezuela \\
\hline Revista Veterinaria & Argentina \\
\hline Slovenian Veterinary Research & Slovenia \\
\hline South African Journal of Animal Science & South Africa \\
\hline Internet Journal of Veterinary Medicine & United States \\
\hline Open Veterinary Science Journal & Netherlands \\
\hline Tropical and Subtropical Agroecosystems & Mexico \\
\hline Turkish Journal of Veterinary and Animal Sciences & Turkey \\
\hline Revista Cientifica & Venezuela \\
\hline Vet Scan & India \\
\hline Veterinaria Mexico & Mexico \\
\hline Veterinarni Medicina & Czech Republic \\
\hline Veterinary Medicine International & United States \\
\hline
\end{tabular}

a Contains publications by any American or Canadian veterinary school or college, 2006-7. 
publishers who have not historically offered journals with embargo periods were removed. Web sites of the remaining titles were then visited individually online, and access to current and previous issues was attempted. Although 13 veterinary-specific journals were identified as having an embargo period, language barriers proved extremely difficult, and this number should be considered a minimum.

Nine of the schools or colleges stated that their institution had no scholarly communication initiatives related to authors' options or OA journals. In those schools with scholarly communication initiatives, such efforts were usually performed at an institutional level, not at a department or liaison-librarian level. Many of the institutions surveyed referenced the mandate that NIHfunded research must be deposited into PubMed Central as the focal point for issues related to scholarly communication. Finally, no veterinary school had language in its tenure requirements that made specific mention of OA journals or alternate forms of information dissemination. Rather, peer review of journals was the most common requirement.

\section{DISCUSSION}

Articles identified as free full text through MEDLINE were either available through PubMed Central, the free digital archive maintained by the $\mathrm{NIH}$, or through a direct link to the publisher. It is important to note that there are exceptions. Specific research papers derived from NIH-funded projects might be available free, and some journals choose to offer free access to only selected articles. Also, some journals make selected issues OA, such as the Journal of Veterinary Medical Education special issue on Animal Welfare in Veterinary Medical Education and Research. ${ }^{24}$ Another exception is when an author deposits an individual copy of a paper into PubMed Central. It is also important to note that occasional problems with access to free full text arise when changes in publishers or platforms occur. As an example, although free full-text links appeared for most articles in the Journal of Dairy Science in 2009, when this article was written those links were missing because of a recent move to another publisher.

When publication patterns for the academic institutions with the highest publication rates were examined closely, a pattern was revealed for the Canadian colleges. The Canadian Veterinary Medical Association (CVMA) publishes two journals, The Canadian Veterinary Journal and the Canadian Journal of Veterinary Research. Both of these journals offer free access to their articles three months ${ }^{a}$ after publication. A PubMed search of these two journal titles during the same 2006-7 period revealed that 51\% of authors had a Canadian address in the record address field. The three highest publication-ranked Canadian veterinary schools, the University of Saskatchewan, Atlantic College, and Université de Montreal, published heavily in these two CVMA journals. Respectively, these schools published $75 \%, 56 \%$, and $33 \%$ of their OA articles in CVMA journals. The University of Guelph in Ontario also continued this trend, publishing 27 (51\%) of its OA articles in CVMA journals. However, a large percentage of its scholarly output was distributed over more journal titles, many of which were not OA.

It is interesting to note the different approaches of the American Veterinary Medical Association (AVMA) and the CVMA. The AVMA publishes two high-impact veterinary journals, the Journal of the American Veterinary Medical Association and American Journal of Veterinary Research. These two AVMA journal titles ranked first and second, respectively, among all journal titles and accounted for $684(14 \%)$ of all $2006-7$ veterinary school or college publications. Unlike the CVMA journals, neither of the AVMA journals are OA nor do they have a policy allowing the archiving of pre-print or post-print content. However, the CVMA receives funding from the Canadian government to help defray some of its publishing costs, facilitating the adoption of a short embargo period.

Other than the policy differences between the major Canadian and American veterinary journals, survey results did not reveal any obvious factors to explain differences in OA publishing between institutions. One possible explanation is that differing departmental strengths or research emphases result in varying discipline-specific publishing patterns. The number of $\mathrm{OA}$ journals varies significantly by discipline, which could result in more articles being available through OA journals at one school or college than another.

Data from Ulrichsweb and DOAJ indicated that $14 \%$ of veterinary journals currently published offer immediate and free full-text access. However, $26 \%$ of the articles in this study were freely available through PubMed Central or links to the publisher's Web site. This difference is due in no small part to these factors: (a) publication in nonveterinary-specific journals (see Table 1), (b) the dominance of a few select journal titles, (c) many smaller veterinary journals not being indexed by MEDLINE, and (d) publication in journals with embargo periods, which accounted for most veterinary publications.

Differences in numbers when discussing issues surrounding OA are also complicated by the different publishing models. For example, articles identified in this survey were published in 679 different journals, with 245 titles providing at least some content free, which means that $36 \%$ of journals of interest to veterinary faculty, staff, and students appear to offer some level of free access. Also of note is how publishing patterns in veterinary medicine revealed in this study reinforce the need for the collaboration of multiple sciences to understand modern biomedical science topics.

Ninety percent of all immediately OA veterinary journal titles identified during this study were published outside North America. One possible reason for this may be the lack of commercial, society, or university press publisher interest in a particular journal because of a small subscription base or poor content quality. In addition, funding from local or national governmental agencies to assist with publication costs may render this model more feasible in other countries. A nation's or educational institution's interest in promoting its scientific productivity could also play a role.

A search of MEDLINE at the time this article was written (August 2010) revealed that 23\% of journal articles pub- 
lished in 2006-7 limited to "humans" $(952,018)$ had links to the free full text $(218,194)$, and $31 \%$ of articles limited to "animals" $(340,677)$ during this same period had links to free full-text $(106,409)$. This finding corroborates Bjork et al.'s 25 finding.

The 26 journal titles that published the largest number of veterinary articles and offered some form of free full-text access accounted for $64 \%$ of all OA articles. However, because only one of these journals offered immediate free access on publication, the dominance of an embargoperiod model is apparent. The appeal of this model to publishers is that it represents a compromise between complete and immediate OA and subscription-only access. The embargo model also offers the perception of guaranteed financial stability, in part because subscribers are less likely to cancel subscriptions when recent articles are not available free. This finding was also reinforced by the significant finding that only eight of the 4,872 articles published were in the three journals offering immediate OA.

Beyond free access through PubMed Central or a journal's Web site, digital IRs may also offer free access to digital works. In the past few years, some large changes have occurred in this area. The Registry of Open Access Repository Material Archiving Policies ${ }^{26}$ illustrates the large number of IRs who have mandates requiring the deposit of publications by faculty, including Harvard, MIT, and Stanford. Of the 31 institutions granting DVM degrees, 24 owned an IR, and many of these were created only recently. In personal communications with veterinary librarians at these institutions, most IRs have received only minor promotion and marketing exposure, and very few were targeted directly to the veterinary school or college.

Additional articles beyond the 1,334 OA articles identified are no doubt available freely through IRs or a subjectbased repository, although determining this availability falls outside the scope of this article. Previous research has shown that more than a third of high-impact MEDLINE-indexed journal articles could be found free at non-journal Web sites. Most of these were found at ".edu" domains, ${ }^{27}$ consistent with US-based academic IRs. SHERPA ${ }^{28}$ is a partnership among many educational institutions that tracks publishers' policies on the selfarchiving of journal articles on the Web and in OA repositories. Currently, $61 \%$ of scientific publishers (approximately 900) compiled by Sherpa-Romeo ${ }^{29}$ formally allow authors to archive post-print or pre-print copies of articles. With little or no active promotion of IRs by the veterinary librarians surveyed, many opportunities currently exist for academic institutions to solicit deposits of the scholarly output of their faculty and staff into their own IRs. Two veterinary colleges, Atlantic Veterinary College and Oregon State University, are already active in identifying and recruiting articles authored by their faculty and published in journals that allow some form of self-archiving for their repositories. It is apparent that most institutions acquired IRs without a complete and properly staffed marketing plan in place. The current financial hardships being experienced at many institutions has probably contributed to this lack of marketing and other promotional efforts.
The lack of specific limitations in the definition of which journals are acceptable for consideration in veterinary schools' and colleges' promotion and tenure process creates an opportunity for those authors considering publishing in OA journals. As a result, the reputation and peer review process for a specific journal should play a greater role in the tenure review process, as well as its accessibility.

\section{SUMMARY}

The free availability of a quarter of information recently published by veterinary faculty, staff, and students in the United States and Canada is significant and valuable, even when it only becomes freely available after an embargo period. The current "One Health" 30 initiative to foster interdisciplinary collaborations and communications in all aspects of health science for animals and humans contains important information elements. Without access to current veterinary discoveries, strategies cannot be put into place to solve tomorrow's health care problems. To truly accelerate biomedical research discoveries and expand the scientific knowledge base, the large players in the veterinary publishing world will need to come together and consider how information might be shared more openly and broadly.

Those veterinary colleges wishing to encourage wider sharing of their school's publication output might consider altering the language in their tenure requirements to explicitly allow or encourage publication in OA journals or deposit into their own IRs.

Although the infrastructure for OA is now well established, the need continues for future effort related to awareness raising and research on $\mathrm{OA}$ and access to veterinary publications. Additionally, exploration of current government funding of veterinary-related journals could prove valuable. Other future research may focus on the availability of veterinary discoveries through subject-specific repositories, professional networking sites, or personal Web pages. Last, the recent creation of many institutional IRs warrants their re-examination in the near future and a mechanism for broadening access to veterinary information.

\section{NOTE}

a This was changed to six months in July 2010.

\section{ACKNOWLEDGMENT}

The author thanks Laura B. Krueger, Nicole TheisMahon, and Erin Park for their assistance with data collection and manipulation and the many veterinary librarians who responded to the survey. Nicole TheisMahon, Linda Watson, and Laurie Anderson and many anonymous reviewers provided helpful comments on the manuscript.

\section{REFERENCES}

1 Sathe NA, Grady JL, Giuse NB. Print versus electronic journals: a preliminary investigation into the effect of journal format on research processes. J Med Libr Assoc. 2002;90(2):235-43. 
2 Tenopir C, King DW, Bush A. Medical faculty's use of print and electronic journals: changes over time and in comparison with scientists. J Med Libr Assoc.

2004;92(2):233-41.

3 Schlimgen JB, Kronenfeld MR. Update on inflation of journal prices: Brandon/Hill list journals and the scientific, technical, and medical publishing market. J Med Libr Assoc. 2004;92(3):307-14.

4 American Animal Hospital Association, American Veterinary Medical Association. Digital clinic study [Internet]. Lakewood (CO): American Animal Hospital Association; 2008 Feb 18 [cited 2010 Dec 26]. Available from: http://www.aahanet.org/PublicDocuments/ DigitalClinicSurveyReport.pdf.

5 World Health Organization [Internet]. Geneva: The Organization; c2011 [cited 2010 Aug 24]. HINARI access to research in health programme; [about 4 screens]. Available from: http://www.who.int/hinari/en/

6 Food and Agriculture Organization of the United Nations[Internet]. Rome: The Organization; c2011 [cited 2010 Dec 16]. About AGORA; [about 3 screens]. Available from: http://www.aginternetwork.org/en/ index.jsp

7 Möller AM. The case for open access publishing, with special reference to open access journals and their prospects in South Africa. Belleville: Department of Library and Information Science, University of the Western Cape; 2006.

8 Kyrillidou M, Young M. ARL Statistics, 2005-06: a compilation of statistics from the one hundred and twenty-three members of the Association of Research Libraries. Washington (DC): Association of Research Libraries; 2008. p. 136.

9 Bureau of Labor Statistics, US Department of Labor. Consumer price index-all urban consumers [Internet]. Washington (DC): The Bureau; c2010 [cited 2010 Dec 16]. Available from: http://data.bls.gov/pdq/ SurveyOutputServlet?data_tool=latest_numbers\& series_id=CUUR0000SA0\&output_view=pct_1mth.

10 National Institutes of Health. NIH public access policy [Internet]. Bethesda (MD): The Institutes; n.d. [cited 2010 Dec 16]. Available from:

http://publicaccess.nih.gov/policy.htm.

11 BioMed Central [Internet]. London: BioMed Central Ltd.; c1999-2011[cited 2010 Aug 26].Available from: http://www.biomedcentral.com/

12 Lawrence $S$. Free online availability substantially increases a paper's impact. Nature. 2001;411:521.

13 Eysenbach G. Citation advantage of open access articles. PLOS Biol. 2006;4(5):e157.

doi:10.1371/journal.pbio.0040157

14 Hajjem C, Harnad S, Gingras Y. Ten-year crossdisciplinary comparison of the growth of open access and how it increases research citation impact. IEEE Data Eng Bull. 2006;28(4):39-47.

15 Antelman K. Do open-access articles have a greater research impact? Coll Res Lib. 2004;65(5):372-82.
16 Davis PM, Lewenstein BV, Simon DH, Booth JG, Connolly MJL. Open access publishing, article downloads, and citations: randomised controlled trial. Brit Med J. 2008;337:a568. doi:10.1136/bmj.a568

17 Craig ID, Plume AM, McVeigh ME, Pringle J, Amin $\mathrm{M}$. Do open access articles have greater citation impact? a critical review of the literature. J Informetr. 2007;1(3):239-48. doi:10.1016/j.joi.2007.04.001

18 Evans JA, Reimer J. Open access and global participation in science. Science. 2009;323(5917):1025. doi:10.1126/science.1154562

19 Chan L, Kirsop B, Arunachalam S [Internet]. London: Science and Development Network; c2011 [2005; cited 2010 Dec 16]. Open access archiving: the fast track to building research capacity in developing countries. 2005. Available from: http://www.scidev.net/en/features/ open-access-archiving-the-fast-track-to-building-r.html

20 PubMed [Internet]. Bethesda (MD): National Center for Biotechnology Information [updated 2009 Oct 28; cited 2010 Aug 25]. Available from: http://www.ncbi.nlm.nih.gov/pubmed/.

21 RefWorks [Internet]. Bethesda (MD): RefWorks; c2009 [cited 2010 Aug 27] Available from: http://www.refworks.com/.

22 Ulrichsweb [Internet]. Seattle (WA): SerialsSolutions; c2011 [cited 2010 Aug 24]. Available from:

http://www.ulrichsweb.com/ulrichsweb/.

23 Directory of open access journals [Internet]. Lund, Sweden: Lund University Libraries; c2011 [cited 2010 Aug 25]. Available from:

http://www.doaj.org/doaj?func=home.

24 Baker HJ, editor. Animal welfare in veterinary medical education and research [Special issue]. J Vet Med Educ. 2010;37(1).

25 Bjork BC, Welling P, Laakso M, Majlender P, Hedlund T, Gudnason G. Open access to the scientific journal literature: situation 2009. PLoS ONE. 2010;5(6):e11273.

26 Registry of Open Access Repository Material Archiving Policies. Southampton, UK: University of Southampton; c2010 [cited 2010 Aug 25]. Available from: http://www.eprints.org/openaccess/policysignup/.

27 Wren JD. Open access and openly accessible: a study of scientific publications shared via the Internet. Brit Med J. 2005;330:1128. doi:10.1136/bmj.38422.611736.E0

28 Eprints.org [Internet]. Nottingham, UK: University of Nottingham, Centre for Research Communications [cited 2010 Aug 22]. SHERPA/RoMEO-publisher copyright policies and self-archiving; [about 1 screen]. Available from http://www.sherpa.ac.uk/romeo/.

29 Eprints.org [Internet]. Nottingham, UK: University of Nottingham, Centre for Research Communications [cited 2009 Jul 21]. Journal policies-summary statistics so far. Available from: http://romeo.eprints.org/stats.php.

30 One Health Initiative [Internet]. [cited 2010 Aug 30]. Available from: http://www.onehealthinitiative.com/index.php. 


\section{AUTHOR INFORMATION}

André J. Nault, MLS, is Head, Veterinary Medical Library, and Adjunct Assistant Professor in Veterinary Clinical Sciences, University of Minnesota, 1971 Commonwealth Avenue, St. Paul, MN 55108 USA. E-mail: naulta@umn.edu. He had a background as a wildlife researcher and veterinary practice manager before going into academic librarianship. His current research interests include veterinary informatics and open access. 